\title{
Utility of GenBank and the Barcode of Life Data Systems (BOLD) for the identification of forensically important Diptera from Belgium and France
}

\author{
Gontran Sonet', Kurt Jordaens ${ }^{2,3}$, Yves Braet ${ }^{4}$, Luc Bourguignon ${ }^{4}$, Eréna Dupont ${ }^{4}$, \\ Thierry Backeljau ${ }^{1,3}$, Marc De Meyer ${ }^{2}$, Stijn Desmyter ${ }^{4}$
}

I Royal Belgian Institute of Natural Sciences, OD Taxonomy and Phylogeny (JEMU), Vautierstraat 29, 1000 Brussels, Belgium 2 Royal Museum for Central Africa, Department of Biology (JEMU), Leuvensesteenweg 13, 3080 Tervuren, Belgium 3 University of Antwerp, Evolutionary Ecology Group, Groenenborgerlaan 171, 2020 Antwerp, Belgium 4 National Institute of Criminalistics and Criminology, Vilvoordsesteenweg 100, 1120 Brussels, Belgium

Corresponding author: Gontran Sonet (gontran.sonet@naturalsciences.be)

Academic editor: Z. T. Nagy | Received 1 August 2013 | Accepted 13 November 2013 | Published 30 December 2013

Citation: Sonet G, Jordaens K, Braet Y, Bourguignon L, Dupont E, Backeljau T, De Meyer M, Desmyter S (2013) Utility of GenBank and the Barcode of Life Data Systems (BOLD) for the identification of forensically important Diptera from Belgium and France. In: Nagy ZT, Backeljau T, De Meyer M, Jordaens K (Eds) DNA barcoding: a practical tool for fundamental and applied biodiversity research. ZooKeys 365: 307-328. doi: 10.3897/ zookeys.365.6027

\begin{abstract}
Fly larvae living on dead corpses can be used to estimate post-mortem intervals. The identification of these flies is decisive in forensic casework and can be facilitated by using DNA barcodes provided that a representative and comprehensive reference library of DNA barcodes is available.

We constructed a local (Belgium and France) reference library of 85 sequences of the COI DNA barcode fragment (mitochondrial cytochrome $c$ oxidase subunit I gene), from 16 fly species of forensic interest (Calliphoridae, Muscidae, Fanniidae). This library was then used to evaluate the ability of two public libraries (GenBank and the Barcode of Life Data Systems - BOLD) to identify specimens from Belgian and French forensic cases. The public libraries indeed allow a correct identification of most specimens. Yet, some of the identifications remain ambiguous and some forensically important fly species are not, or insufficiently, represented in the reference libraries. Several search options offered by GenBank and BOLD can be used to further improve the identifications obtained from both libraries using DNA barcodes.
\end{abstract}

\section{Keywords}

Forensic entomology, COI, DNA barcoding, BLAST

Copyright Gontran Sonet et al. This is an open access article distributed under the terms of the Creative Commons Attribution International License (CC BY 4.0), which permits unrestricted use, distribution, and reproduction in any medium, provided the original author and source are credited. 


\section{Introduction}

Insects collected on crime scenes can be used to estimate the time elapsed between death and corpse discovery, i.e. the post mortem interval or PMI (Rodriguez and Bass 1983, Joseph et al. 2011, Charabidze 2012). The correct identification of these insects is decisive in forensic casework since different species may have different developmental times under identical conditions. Erroneous identifications can therefore bias PMI estimates (Wells et al. 2001). DNA-based identification can be a valuable tool to identify immature life stages (Meiklejohn et al. 2013), fragments of insects, empty puparia (e.g. Mazzanti et al. 2010) or specimens of morphologically similar species (e.g. Meiklejohn et al. 2011, Jordaens et al. 2012). This technique relies on the comparison of a query sequence obtained from a sample collected at a crime scene with a library of reference sequences from well-identified specimens. The reference sequence showing the highest sequence similarity (= best match) with the query sequence can be used for its identification. However, the validity of this approach depends particularly on the reference library, which has to be representative, comprehensive and without misidentification or sequencing error (Wells and Stevens 2008).

In order to be of interest in court, species identifications provided by a specific reference library should be validated by assessing the likelihood of incorrect identifications using that library (Wells and Williams 2007, Wells and Stevens 2008). Sequences of a particular reference library may allow the correct identification of all species included in the library. However, if this library contains a limited set of species and ignores closely related species, then the likelihood of misidentifications is real (Wells and Stevens 2008). Moreover, the use of a reference library assembled in a different geographic area can also lead to incorrect species assignments because of geographic population structuring or eventual local hybrids (Stevens et al. 2002). Therefore, surveying local entomofaunas is a prerequisite for forensic specimen identifications (Vanin et al. 2008, Caine et al. 2009, Rolo et al. 2013). Likewise, assessing intraspecific variation and geographic substructuring is very important in forensic entomology (Wells and Williams 2007, Harvey et al. 2008, Desmyter and Gosselin 2009, Sonet et al. 2012).

The presence of pseudogene sequences and misidentified specimens in reference libraries is another problem that can constrain identification success (Wells and Stevens 2008). In order to minimise the risk of misidentifications caused by pseudogenes, an additional identification could be performed on the basis of an additional DNA fragment situated in another part of the mitochondrial genome (for example cytochrome b). Since most pseudogenes of mitochondrial origin are relatively short, the chance of sequencing two pseudogenes would drop substantially. Besides pseudogenes, sequences from misidentified specimens may be difficult to distinguish from haplotypes that are shared between correctly identified specimens from two different species (Whitworth et al. 2007). Increased sampling sometimes broadens the ranges of intra- and interspecific sequence divergences, even up to the point that they start overlapping so much that it becomes difficult to distinguish between the species (Wells et al. 2007). 
Accurate identification of forensically important insects has been obtained using mitochondrial markers like the cytochrome $c$ oxidase subunits I and II (COI and COII), cytochrome $b, 16 \mathrm{~S} \mathrm{rDNA}$, NADH dehydrogenase subunit 5 , as well as nuclear markers like the ribosomal internal transcribed spacers 1 and 2, and the developmental gene bicoid (Sperling et al. 1994, Wells and Sperling 2000, Zehner et al. 2004, Guo et al. 2010, Li et al. 2010, Wang et al. 2010, Guo et al. 2011, Zaidi et al. 2011, Park et al. 2013). Among these markers, COI and COII have been predominantly used in forensic entomology (Sperling et al. 1994, Malgorn and Coquoz 1999, Vincent et al. 2000, Wallman and Donnellan 2001, Wells et al. 2001, Wells and Sperling 2001, Harvey et al. 2003, 2008, Wells and Stevens 2008, Liu et al. 2011, Boehme et al. 2012, Jordaens et al. 2012, Renaud et al. 2012). Coincidentally, a fragment of the 5' end of COI has been selected as the standard barcode marker for animal identification by the Consortium for the Barcode of Life (Hebert et al. 2003). DNA barcodes are linked to voucher specimens and are associated with additional information such as primer data and trace files. This practice allows to verify the quality of sequences and to re-examine the organism from which the DNA was extracted (Ratnasingham and Hebert 2007). Barcodes are deposited in the Barcode of Life Data Systems (BOLD) and are tagged as barcodes in GenBank. Consequently, the 5' end of COI is readily available in public reference libraries for a wide variety of dipterans of forensic interest (Wells and Stevens 2008).

In Western Europe, COI sequences from ca. 50 species of Sarcophagidae, ca. 10 species of Calliphoridae and five species of Muscidae are currently available as reference data for the identification of dipterans of forensic interest (Boehme et al. 2012, Jordaens et al. 2012). Specimens of seven species of Sarcophagidae and six species of Calliphoridae are from Belgium (Desmyter and Gosselin 2009, Jordaens et al. 2012, Marinho et al. 2012, Sonet et al. 2012). In this paper, we first extend the reference library of COI sequences with Belgian and French specimens of forensic interest belonging to two families (Calliphoridae and Muscidae) and secondly, we use these new sequences as queries to assess the validity of the identifications provided by GenBank and BOLD.

\section{Methods}

\section{Specimens}

We collected 85 adult specimens of 16 dipteran species of forensic interest from 24 localities in Belgium and three localities in France (Table 1). All Belgian specimens came from forensic cases. Three specimens from three species (Neomyia cornicina, Polietes lardarius and Eudasyphora cyanella) were collected on corpses but are currently not used for the calculation of the PMI. The French specimens of Chrysomya albiceps and Lucilia sericata were not collected on corpses, but were added because of their forensic interest. Morphological species identification was done by two taxonomic experts of Diptera (YB and ED), using five identification keys (D’Assis Fonseca 1968, Bě̌-Bienko 1988, 


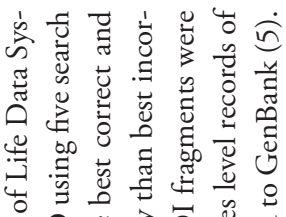

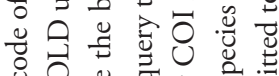
弐 돈 8 을 a पु

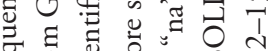

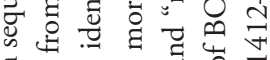
舵 ङ

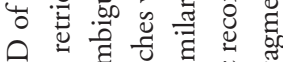

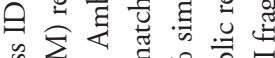
乡̋ ज 苟

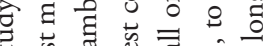

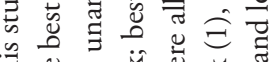

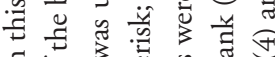

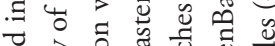

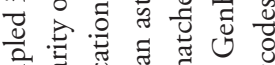

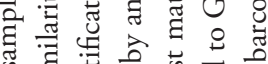

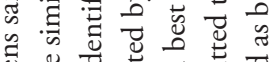

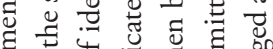

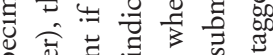

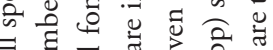

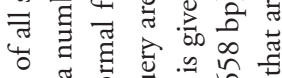
$\Xi \widetilde{g}$ .6.

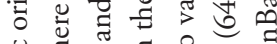

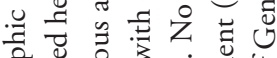

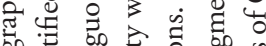

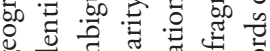

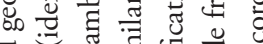

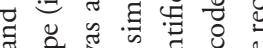

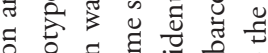
둥

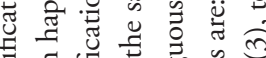

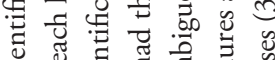
믐 उٓ

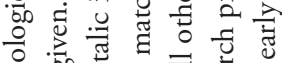
的政 न

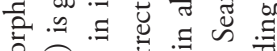
○.

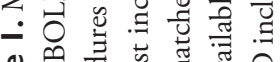

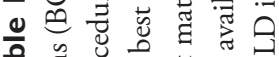

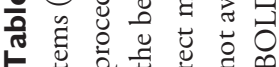

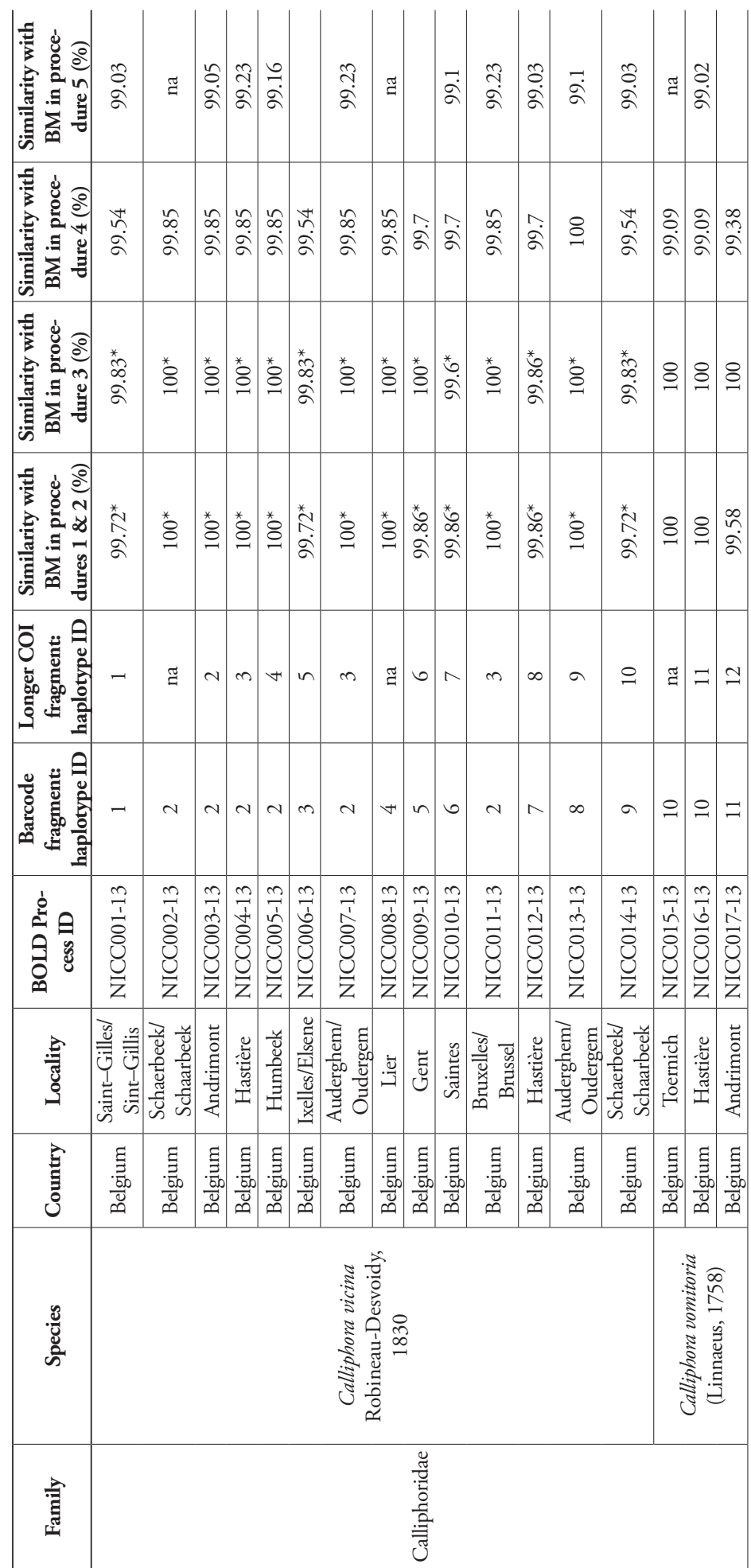




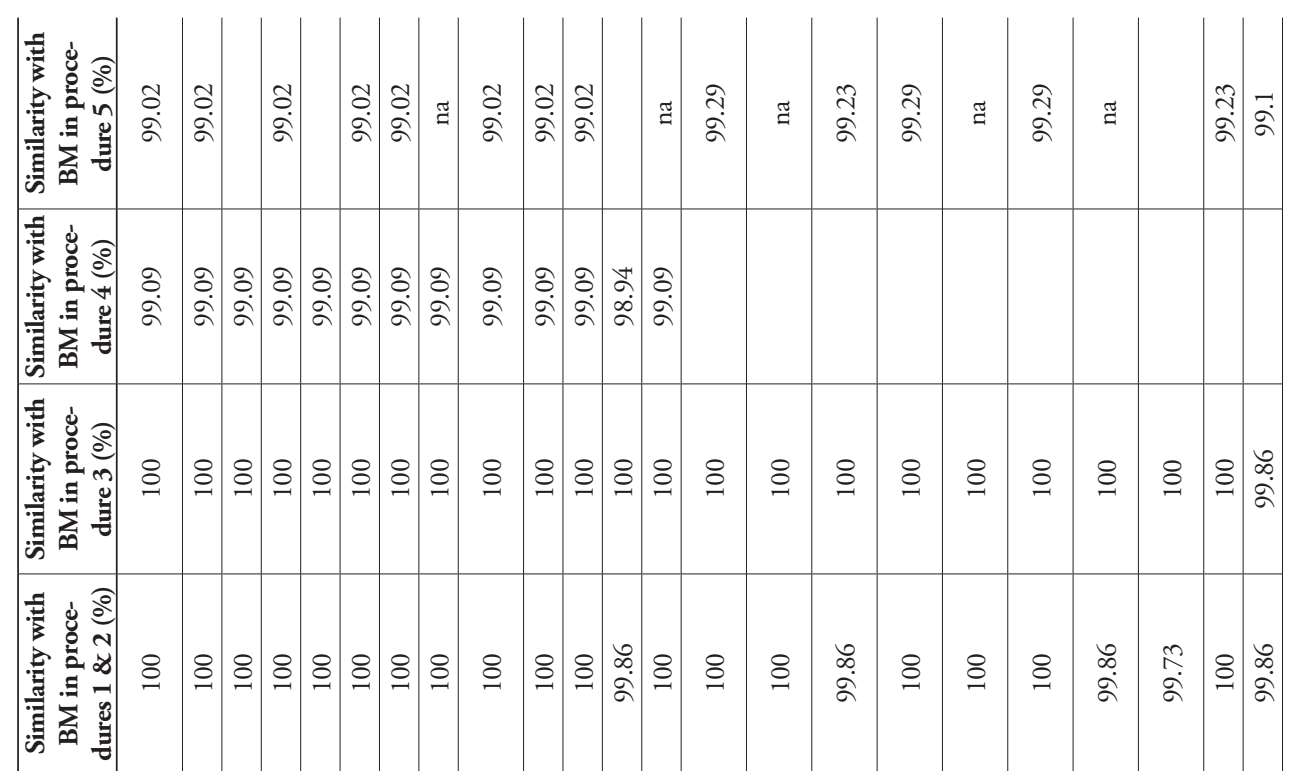

○ิ

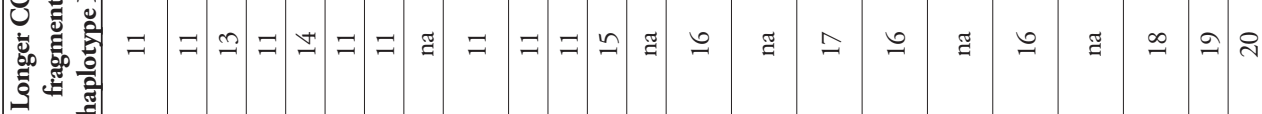

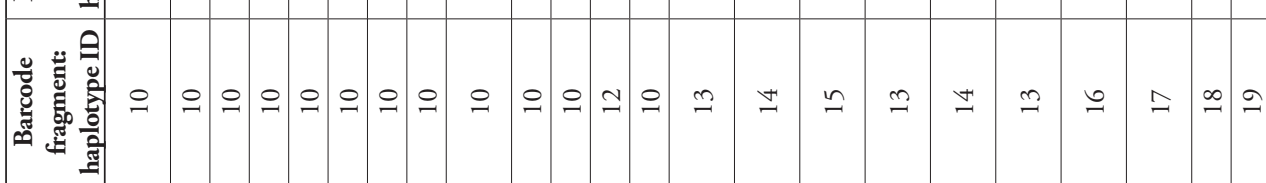

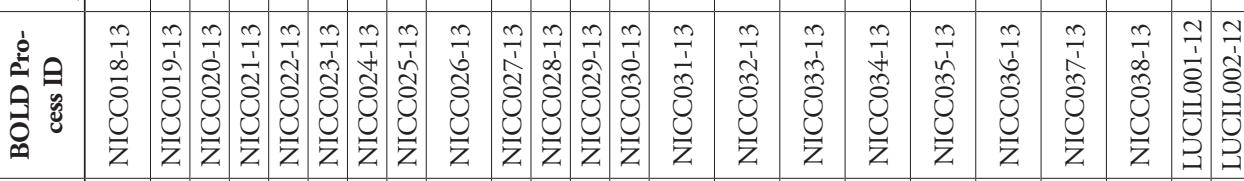

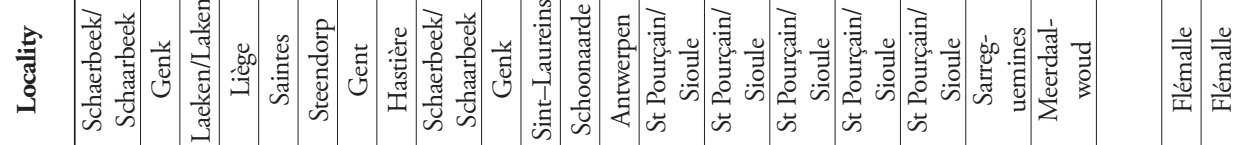

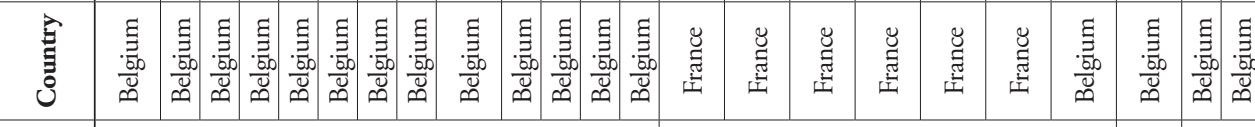

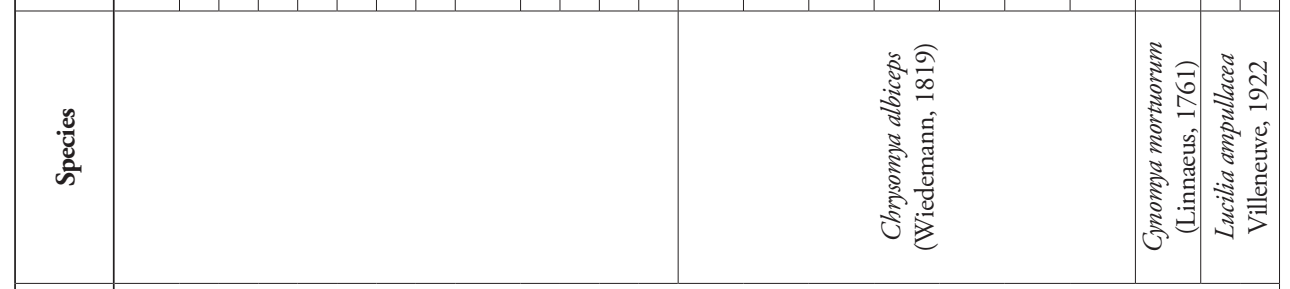




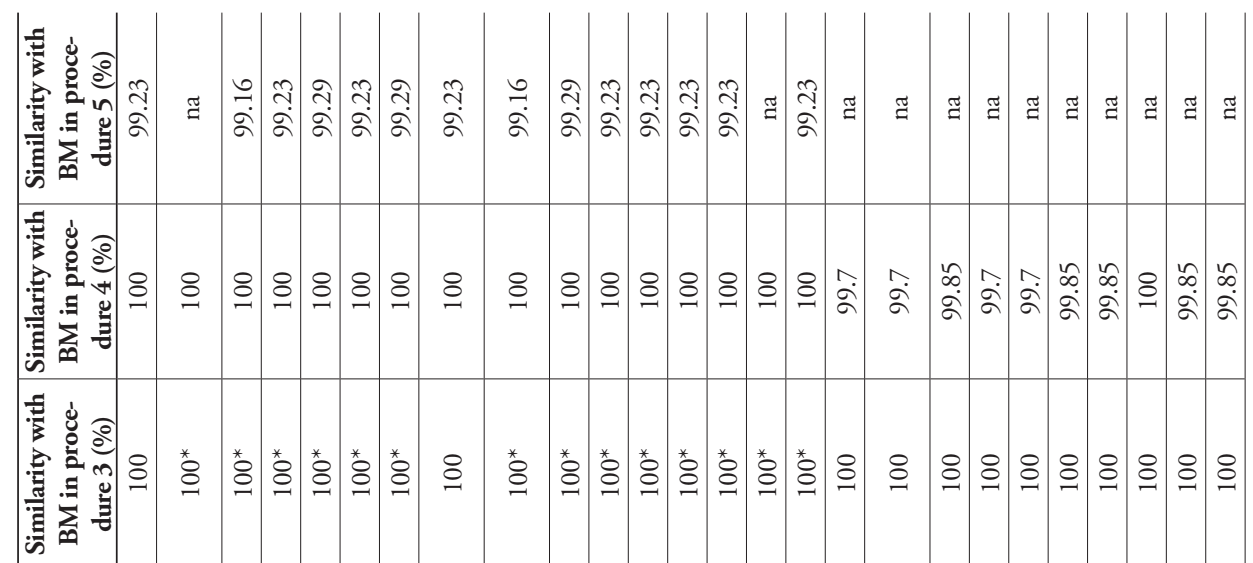

造

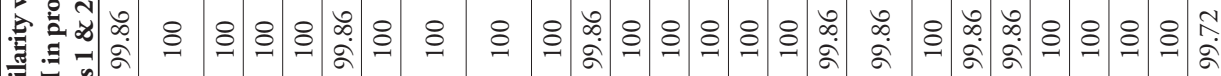

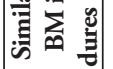

○

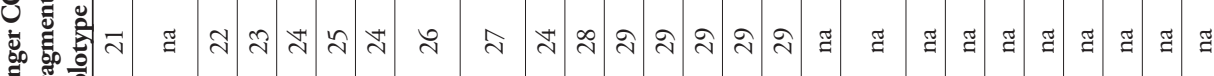
폰 현

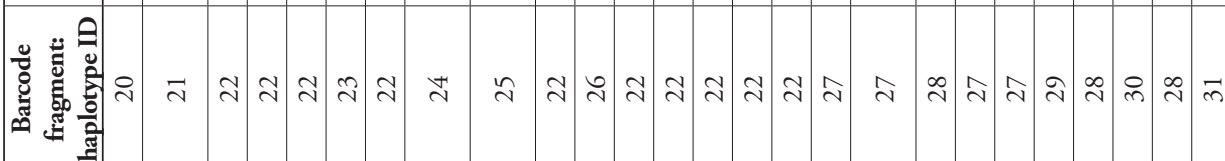

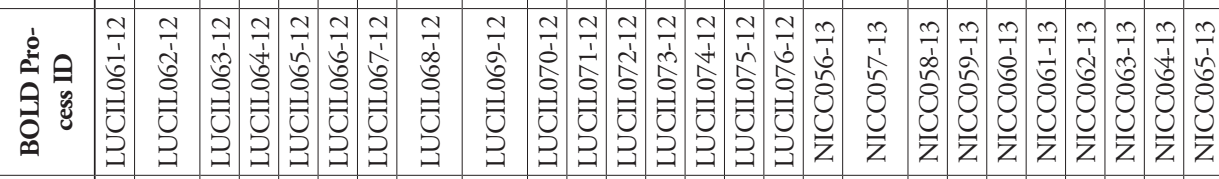

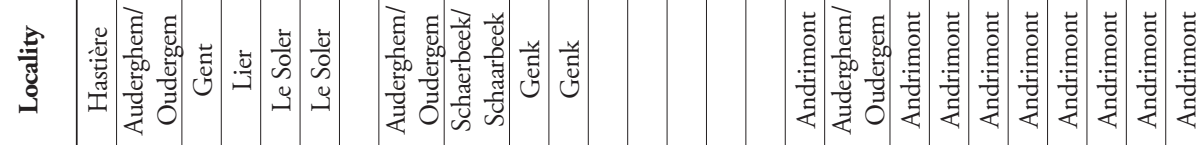

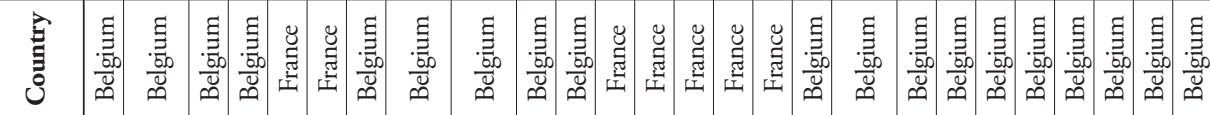

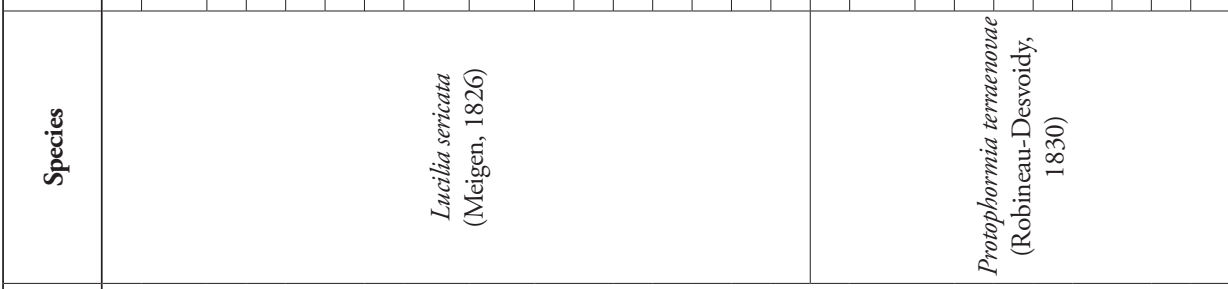

㕇 


\begin{tabular}{|c|c|c|c|c|c|c|c|c|c|c|c|c|c|c|c|c|c|c|}
\hline 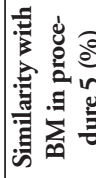 & $\approx$ & $\dddot{g}$ & & & & & & & & & & & & & & $\dddot{\dddot{Z}}$ & & \\
\hline 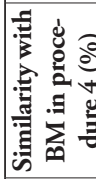 & $\begin{array}{l}n \\
\infty \\
\alpha \\
\alpha\end{array}$ & $\widehat{\alpha}$ & & & & & & 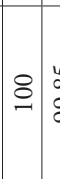 & 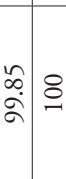 & $\cong \cong$ & @ & & & & & & & \\
\hline 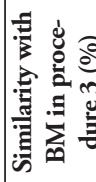 & 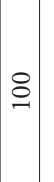 & 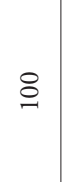 & 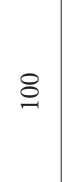 & 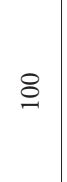 & & 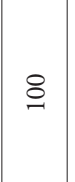 & 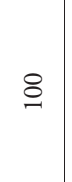 & 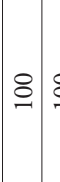 & \& & $\stackrel{8}{Ð}$ & 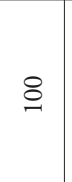 & $\begin{array}{l}n \\
\infty \\
\alpha\end{array}$ & $\begin{array}{l}\hat{n} \\
\dot{\alpha} \\
\alpha\end{array}$ & \& & 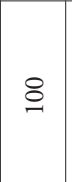 & 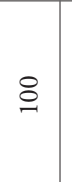 & & $\begin{array}{l}\infty \\
\ddot{\alpha} \\
\check{\alpha}\end{array}$ \\
\hline 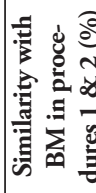 & 8 & $\begin{array}{l}\stackrel{0}{ } \\
\check{a}\end{array}$ & & & & 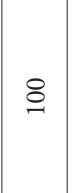 & 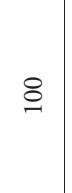 & 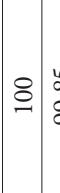 & 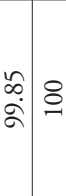 & $\stackrel{8}{-}$ & 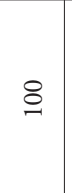 & & & & & & & $\begin{array}{l}\infty^{+1} \\
\stackrel{\alpha}{\alpha}\end{array}$ \\
\hline 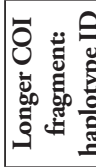 & $\approx$ & 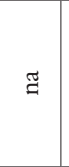 & $\stackrel{n}{~}$ & $\vec{n}$ & $\approx$ & $\tilde{m}$ & $\stackrel{m}{m}$ & $\tilde{m}$ & $\stackrel{m}{m}$ & $\hat{n} \tilde{m}$ & $\stackrel{m}{m}$ & $\hat{m}$ & $\mathscr{g}$ & 아 & 아 & $\dddot{g}$ & $F$ & F \\
\hline 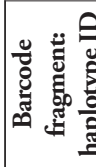 & $\stackrel{\infty}{\sim}$ & $\hat{\lambda}$ & กี & $\tilde{n}$ & 鬲 & $\tilde{n}$ & $\stackrel{n}{n}$ & के & $\stackrel{m}{m}$ & $\hat{m} \hat{m}$ & $\hat{n}$ & $\hat{m}$ & ले & 아 & 아 & of & $\bar{\forall}$ & $\stackrel{F}{F}$ \\
\hline 离目 & 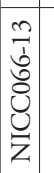 & $\begin{array}{l}n \\
\mathbb{1} \\
\delta \\
8 \\
0 \\
Z\end{array}$ & $\begin{array}{l}n \\
\dot{0} \\
\dot{8} \\
\dot{d} \\
0 \\
z\end{array}$ & 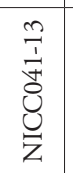 & 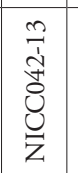 & 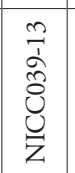 & 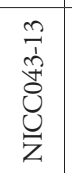 & 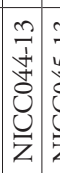 & 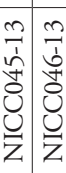 & 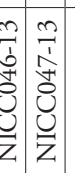 & $\begin{array}{l}n \\
0 \\
\infty \\
d \\
d \\
0 \\
\vdots \\
z\end{array}$ & 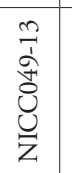 & 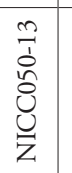 & 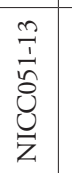 & 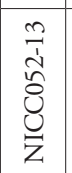 & 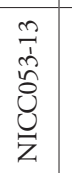 & 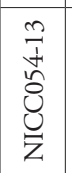 & $\begin{array}{l}n \\
\tilde{n} \\
\tilde{\hat{n}} \\
\dot{8} \\
\tilde{z}\end{array}$ \\
\hline 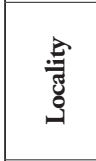 & 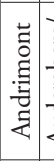 & 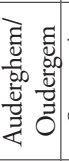 & 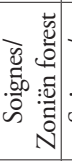 & 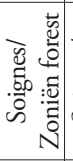 & 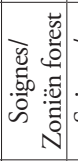 & 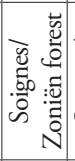 & 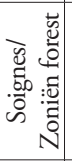 & $\widetilde{g}$ & 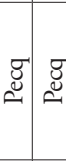 & 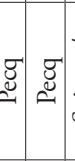 & 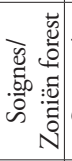 & 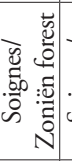 & 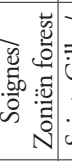 & 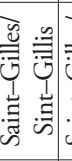 & 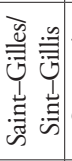 & 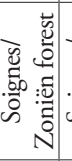 & 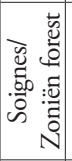 & 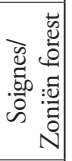 \\
\hline 館 & 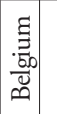 & 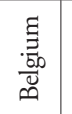 & 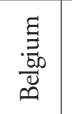 & 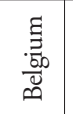 & 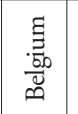 & 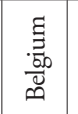 & 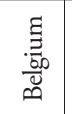 & 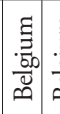 & 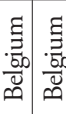 & 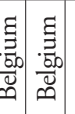 & 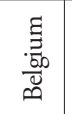 & 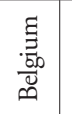 & 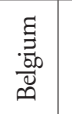 & 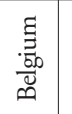 & 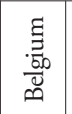 & 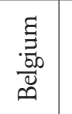 & 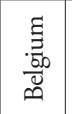 & 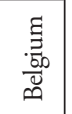 \\
\hline $\begin{array}{l}\text { ֻूँّ } \\
\text { के }\end{array}$ & & & 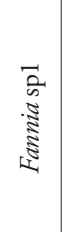 & $\begin{array}{l}\text { है } \\
\text { है } \\
\text { है }\end{array}$ & $\begin{array}{l}n \\
\text { के } \\
\text { है } \\
\text { है } \\
\text { L }\end{array}$ & 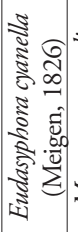 & 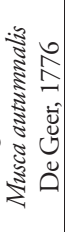 & & & 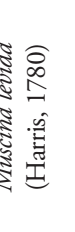 & & & & 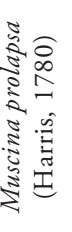 & & & 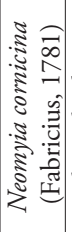 & 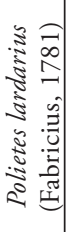 \\
\hline 를 & & & & 蚫 & & & & & & & & 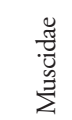 & & & & & & \\
\hline
\end{tabular}


Rozkošný et al. 1997, Gregor et al. 2002, Szpila 2012). Three Fannia specimens (Fanniidae) could not be identified to the species level and were considered as three putative different species. Specimens were deposited as vouchers at the National Institute of Criminalistics and Criminology in Brussels, Belgium (Table 1).

\section{Laboratory protocols}

We extracted genomic DNA from one or two legs per specimen using the NucleoSpin Tissue Kit (Macherey-Nagel) and a final elution volume of $70 \mu$ l. Fragments of the COI marker were amplified using two primer pairs TY-J-1460/C1-N-2191 and C1J-2183/TL2-N-3014 (Sperling et al. 1994, Wells and Sperling 1999). The fragment obtained with the first primer pair encompasses the barcode region of ca. $650 \mathrm{bp}$ used for animals (Hebert et al. 2003). The assembly of the fragments obtained with both primer pairs generated a sequence of $1534 \mathrm{bp}$ corresponding to the complete COI gene. Each $25 \mu \mathrm{l}$ PCR reaction contained final concentrations of $0.2 \mathrm{mM}$ dNTPs, $0.4 \mu \mathrm{M}$ of each primer, $2.0 \mathrm{mM} \mathrm{MgCl}, 0.5 \mathrm{U}$ of Taq DNA polymerase (Platinum, Invitrogen), $1 \times$ PCR buffer and 2-4 $\mu$ l DNA template. The thermal cycler program consisted of an initial denaturation step of $4 \mathrm{~min}$ at $94^{\circ} \mathrm{C}$, followed by 40 cycles of 30 $s$ at $94^{\circ} \mathrm{C}, 30 \mathrm{~s}$ at $45^{\circ} \mathrm{C}$ and $90 \mathrm{~s}$ at $72{ }^{\circ} \mathrm{C}$; with a final extension of $7 \mathrm{~min}$ at $72^{\circ} \mathrm{C}$. We cleaned PCR products using the NucleoFast96 PCR Kit (Macherey-Nagel) and sequenced them bidirectionally on an ABI 3130 Genetic Analyzer (Applied Biosystems) using the BigDye Terminator Cycle Sequencing Kit v3.1.

\section{Sequence quality control and analysis}

We assembled and aligned sequences in SeqScape v2.5 (Applied Biosystems) and confirmed the absence of stop codons using MEGA5 (Tamura et al. 2011). Sequences were deposited in BOLD (BOLD process ID's are given in Table 1) and GenBank. All different haplotypes were extracted from the aligned sequences using the $\mathrm{R}$ package PEGAS (Paradis 2010). We calculated pairwise p-distances (i.e. the proportion of sites at which two sequences differ) and searched for haplotypes that were shared among species.

Haplotypes were then used as queries to search for most similar sequences in two public databases: GenBank (NCBI, National Centre for Biotechnology Information) and BOLD (the Barcode of Life Data Systems). These most similar sequences will be called "best matches" sensu Meier et al. (2006) in the following. In GenBank, searches were done using MegaBLAST, the Basic Local Alignment Search Tool (BLAST) optimised for highly similar sequences (Zhang et al. 2000, Morgulis et al. 2008). In BOLD, the in-built Identification System (IDS) was applied (Ratnasingham and Hebert 2007) on two different databases: the Public Record Barcode Database $(341,580$ sequences; 45,368 nominal species and 11,732 interim species, or candidate species 
that have not been described yet on 24 May 2013) and the Species Level Barcode Records (1,367,662 sequences; 127,679 species and 53,394 interim species on 24 May 2013). The first database comprises the same records as GenBank because both libraries regularly synchronize their published records. In BOLD, this database of public records is a collection of COI records of minimum $500 \mathrm{bp}$ from the published projects of BOLD. The Species Level Barcode Records of BOLD is used by default in IDS. It contains, in addition to the published COI records, early data release of COI records with a species level identification and a minimum sequence length of $500 \mathrm{bp}$. These early releases contain all information necessary for barcodes (locality and date of sample collection, trace files and sequence information as well as voucher specimen and database identifiers), have passed computerized quality checks of BOLD but might include provisional taxonomic assignments (Hebert et al. 2010).

In total, we applied five search strategies by submitting the barcode sequences to 1) GenBank, 2) the Public Records of BOLD, 3) the Species Level Records of BOLD including early releases, as well as 4) by using the barcode sequences as queries in combination with a keyword, "barcode", in GenBank, and 5) by submitting COI sequences longer than the barcode fragment (1412-1534 bp) to GenBank. The use of the keyword "barcode" allowed us to filter the GenBank reference sequences and obtain only best matches that are tagged as barcodes, not only in the field "keyword" but also in any field of GenBank records. Longer COI sequences have not been submitted to BOLD because BOLD was developed to accept sequences from the strict barcode region only. In BOLD, IDS returns a list of maximum 99 best matches and provides a species-level identification for best close matches showing less than 1\% divergence (Ratnasingham and Hebert 2007). Since BLAST searches are based on approximate alignments (regions of local similarity between sequences), species assignments are usually preferably performed on the basis of local alignments. Hence we verified that the best hits and their percentages of sequence identity obtained from the MegaBLAST searches in GenBank were identical to those (= 1 - p-distance) calculated with MEGA5 (Tamura et al. 2011) using local databases downloaded from GenBank and aligned with CLUSTAL W (Thompson et al. 1994). Identifications were made on the basis of the highly similar best matches (> 99\% similarity), according to the "best close match" method of Meier et al. (2006). We qualified each best match with a similarity of $>99 \%$ as correct if it had the same species name as the query or as incorrect if it had a different species name than the query. In addition, the identification of a query was considered as unambiguous if all best matches with a similarity of $>99 \%$ had the same species name. If this was not the case, then the identification was ambiguous. For each identification, we made sure that best close matches included only records properly identified to the species level by excluding the few records with provisional identifications (a code instead of a nominal species name). We also verified whether the alignment of the query with each best match comprised at least $600 \mathrm{bp}$. When no best match of > 99\% similarity was retrieved for a given query, the presence of conspecific and congeneric barcode sequences of $>500$ bp was investigated in both public libraries. If present, their divergences (p-distances) with the queries were calculated using MEGA5 (Tamura et al. 2011). 


\section{Results}

In total 85 sequences were obtained with more than $641 \mathrm{bp}$ of the COI DNA barcode fragment, representing 42 haplotypes. The majority of them (63 sequences) involved a longer COI fragment (1412-1534 bp), representing 42 other haplotypes. Pairwise intraspecific p-distances ranged from zero to $0.5 \%$ and none of the species represented in this dataset shared haplotypes.

\section{Search procedures 1 and 2}

Using the 42 haplotypes of the barcode region as a query yielded the same results in GenBank and in the Public Record Barcode Database of BOLD. Best matches of > $99 \%$ similarity were retrieved for 36/42 haplotypes, representing 11 out of 16 species (Table 1). These best matches were either identical (17/36) or differed from the query in less than three substitutions (19/36). We obtained at least one correct best match for each query. However, species identifications were either unambiguous (18 queries, 8 species) or ambiguous (18 queries, 3 species). For two queries, best matches included species of another genus: Musca domestica Linnaeus, 1758 was found for Calliphora vicina and Chrysomya megacephala (Fabricius, 1794) for Lucilia ampullacea. In all other cases of ambiguous identification, best matches involved congenerics: Calliphora croceipalpis Jaennicke, 1867 was found for Calliphora vicina, Lucilia cuprina (Wiedemann, 1830) for Lucilia sericata and Lucilia porphyrina (Walker, 1856) for Lucilia ampullacea. Finally, the number of best matches with $>99 \%$ similarity varied from one to more than 99 per query (the number of best matches displayed by BOLD is limited to 99). For five species, less than five sequences with a similarity of $>99 \%$ were retrieved (Figure 1).

For six queries, the best matching similarities were $<93.5 \%$. These included the haplotypes of Fannia sp1, sp2 and sp3, Muscina prolapsa and Neomyia cornicina. There were no COI sequences of Muscina prolapsa or of Neomyia cornicina in GenBank. For Fannia, fragments of the barcode region of $>500$ bp were available for 14 specimens representing four species, viz. Fannia canicularis (Linnaeus, 1761), Fannia scalaris (Fabricius, 1794), Fannia brevicauda Chillcott, 1961 and Fannia serena (Fallen, 1825) but their p-distances with our three Fannia haplotypes ranged from 6.6\% to $16.2 \%$.

\section{Search procedure 3}

Using the Species Level Barcode Records dataset of BOLD (Table 1), highly similar best matches (> 99\%) were retrieved for 40/42 queries (14/16 species). Correct best matches were retrieved for all specimens identified at the species level, but identifications were often ambiguous ( 25 queries, 6 species). This method yielded a higher 


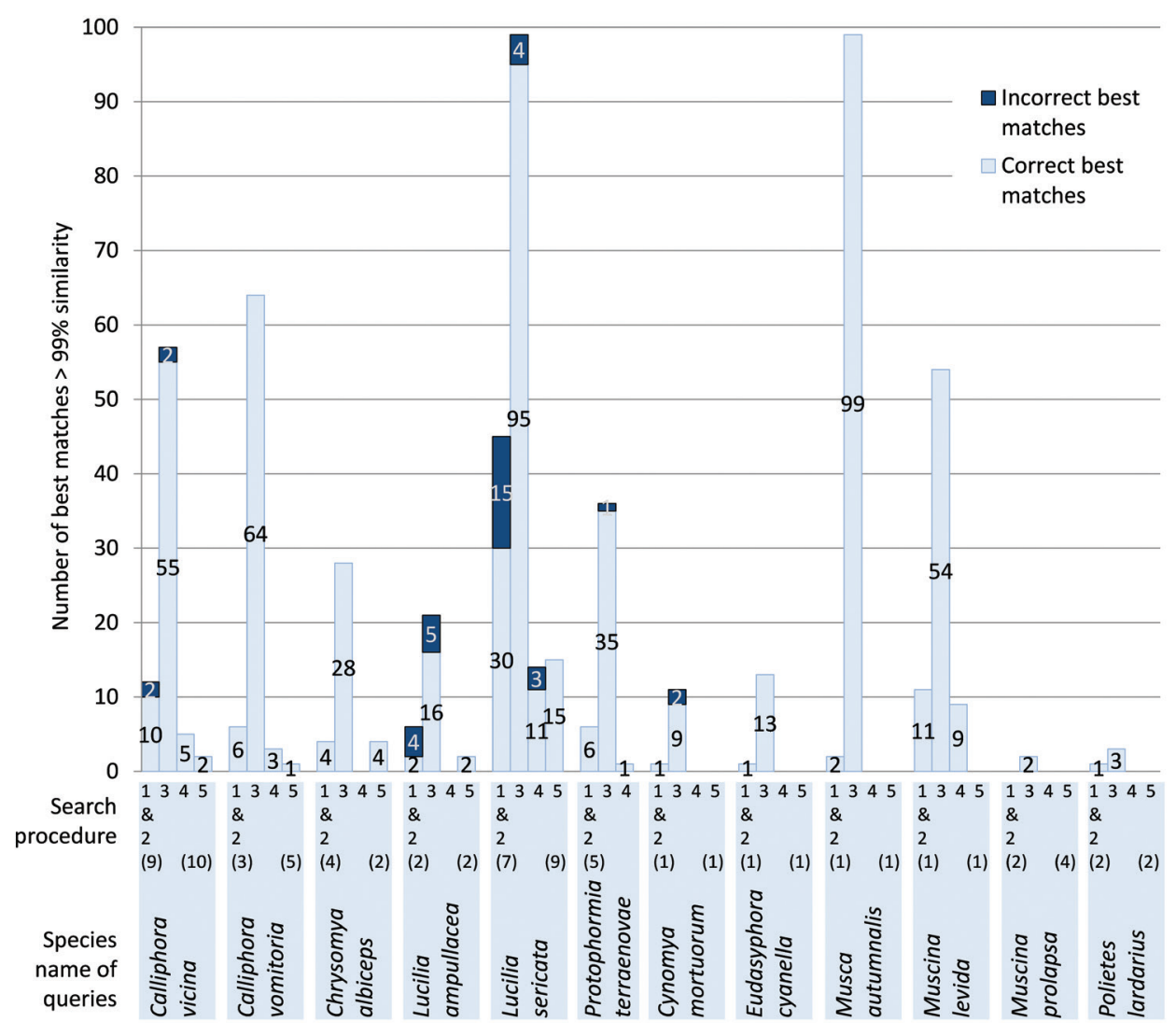

Figure I. Best matches obtained for each species using five different search procedures: Barcode fragment (642-658 bp) submitted to GenBank (1) and the public records of BOLD (2); barcode fragment submitted to the species level records of BOLD, including early-released sequences (3); barcode fragment and keyword "barcode" submitted to GenBank (4) and longer COI fragment (1412-1534 bp) submitted to GenBank (5). Numbers of haplotypes used as queries are between parentheses. Longer COI fragments were obtained for all species except for Protophormia terraenovae.

proportion of best matches of $>99 \%$ similarity than when the search was restricted to public records ( $95 \%$ of the queries instead of $86 \%$ ). However, the proportion of unambiguous identifications was smaller (38\% instead of $50 \%$ of the queries; Table 2). Yet, in contrast to all the other searches, early-released sequences provided two correct matches for Muscina prolapsa, one match for Fannia sp2 and three matches for Fannia sp1 (correct at the genus level). The latter identification was ambiguous since two best matches showed 100\% similarity with Fannia lustrator (Harris, 1780) and one showed $99.85 \%$ similarity with $F$. pallitibia (Rondani, 1866). The two queries for which best matches were of $<99 \%$ similarity were from Fannia sp3 and Neomyia cornicina. No barcodes were available for Neomyia cornicina in BOLD. 
Table 2. Evaluation of the DNA-based identifications obtained in this study using five search procedures: barcode fragment submitted to GenBank (1), to the public records of BOLD (2), to the species level records of BOLD including early releases (3), to the records of GenBank that are tagged as barcodes (4) and longer COI fragment submitted to GenBank (5). Only best matches of $>99 \%$ similarity were considered. OK: correct unambiguous identification; $\mathrm{OK}+$ : ambiguous identification due to correct and incorrect best matches (species names associated with incorrect best matches are given with the abbreviated genus name in case of congeneric matches); *: ambiguous identifications where the best correct and the best incorrect matches had the same similarity with the query; best correct matches were more similar to the query than best incorrect matches in all other ambiguous identifications; na: longer COI fragment not available; empty cell: no best match above $99 \%$ similarity. Numbers without parentheses were obtained with the barcode fragment and numbers between parentheses were obtained with the longer COI fragment. In order to allow comparisons between the results obtained with the barcode and the longer COI datasets, values obtained with the barcode fragment of the sequences for which the longer COI fragment was available are given between brackets.

\begin{tabular}{|c|c|c|c|c|c|}
\hline \multirow{2}{*}{ Species } & \multirow{2}{*}{$\begin{array}{l}\text { Number of } \\
\text { haplotypes }\end{array}$} & \multicolumn{4}{|c|}{ Search procedure } \\
\hline & & $1 \& 2$ & 3 & 4 & 5 \\
\hline Calliphora vicina & $9(10)$ & $\begin{array}{l}\text { OK }+ \text { C. croceipalpis*, } \\
\text { Musca domestica* }\end{array}$ & $\begin{array}{l}\mathrm{OK}+\text { C. croceipalpis* } \\
\text { Musca domestica* }\end{array}$ & OK & OK \\
\hline Calliphora vomitoria & $3(5)$ & OK & OK & $\mathrm{OK}$ & OK \\
\hline Chrysomya albiceps & $4(2)$ & OK & OK & & OK \\
\hline Lucilia ampullacea & $2(2)$ & \begin{tabular}{c|}
$\mathrm{OK}+$ L. porphyrina, \\
Chrysomya megacephala
\end{tabular} & $\begin{array}{c}\text { OK }+ \text { Chrysomya } \\
\text { megacephala }\end{array}$ & & OK \\
\hline Lucilia sericata & $7(9)$ & $\mathrm{OK}+$ L. cuprina & $\mathrm{OK}+$ L. cuprina* & $\begin{array}{l}\mathrm{OK}+L . \\
\text { cuprina }\end{array}$ & $\begin{array}{l}\mathrm{OK}+L . \\
\text { cuprina }\end{array}$ \\
\hline $\begin{array}{c}\text { Protophormia } \\
\text { terraenovae }\end{array}$ & $5(0)$ & OK & $\mathrm{OK}+$ P. uralensis & OK & na \\
\hline Fannia sp1 & $1(1)$ & & $\begin{array}{l}\text { F. pallitibia, } \\
\text { F. lustrator }\end{array}$ & & \\
\hline Fannia sp2 & $1(1)$ & & F. manicata & & \\
\hline Fannia sp3 & $1(1)$ & & & & \\
\hline Cynomya mortuorum & $1(1)$ & $\mathrm{OK}$ & $\mathrm{OK}+$ C. cadaverina & & \\
\hline Eudasyphora cyanella & $1(1)$ & $\mathrm{OK}$ & $\mathrm{OK}$ & & \\
\hline Musca autumnalis & $1(1)$ & $\mathrm{OK}$ & $\mathrm{OK}$ & & \\
\hline Muscina levida & $2(4)$ & $\mathrm{OK}$ & $\mathrm{OK}$ & $\mathrm{OK}$ & \\
\hline Muscina prolapsa & $2(2)$ & & $\mathrm{OK}$ & & \\
\hline Neomyia cornicina & $1(1)$ & & & & \\
\hline Polietes lardarius & $1(1)$ & $\mathrm{OK}$ & $\mathrm{OK}$ & & \\
\hline \multicolumn{2}{|c|}{$\begin{array}{c}\% \text { of species with matches }>99 \% \\
\text { similarity }\end{array}$} & $69[67]$ & $88[87]$ & 31 [27] & (33) \\
\hline \multicolumn{2}{|c|}{$\begin{array}{l}\% \text { of queries with matches }>99 \% \\
\text { similarity }\end{array}$} & $86[86]$ & $95[95]$ & $62[67]$ & (67) \\
\hline \multicolumn{2}{|c|}{$\%$ of species with unambiguous ID } & $73[70]$ & $57[62]$ & $80[75]$ & $(80)$ \\
\hline \multicolumn{2}{|c|}{$\%$ of queries with unambiguous ID } & $50[42]$ & $38[42]$ & $73[68]$ & $(68)$ \\
\hline \multicolumn{2}{|c|}{$\%$ of species with ambiguous ID } & $27[30]$ & $43[38]$ & $20[25]$ & $(20)$ \\
\hline \multicolumn{2}{|c|}{$\%$ of queries with ambiguous ID } & $50[58]$ & $62[58]$ & $27[32]$ & $(32)$ \\
\hline
\end{tabular}




\section{Search procedure 4}

When both the barcode sequences and the keyword "barcode" were used as queries in GenBank, we retrieved best matches of $>99 \%$ similarity for Calliphora vicina, Calliphora vomitoria, Lucilia sericata, Protophormia terraenovae and Muscina levida (Tables 1 and 2). All best matches of $>99 \%$ similarity were correct and provided unambiguous identifications except for Lucilia sericata, which matched with both correct and incorrect species names (Lucilia cuprina and Lucilia sericata).

\section{Search procedure 5}

Haplotypes of longer COI fragments (1412-1534 bp) were also submitted to a MegaBLAST search on GenBank. Best matches of > 99\% similarity were obtained for all haplotypes of Calliphora vicina, Calliphora vomitoria, Chrysomya albiceps, Lucilia ampullacea and Lucilia sericata. Like in the previous analysis, all best matches were correct and provided unambiguous identifications except for Lucilia sericata (best matches included Lucilia sericata and Lucilia cuprina).

\section{Discussion} Towards a COI reference database for the forensically important dipterans in
Western Europe

With this study we contributed to the establishment of a local COI reference library for fly species of forensic importance in Belgium and France. As such, we provide the first barcodes for Muscina prolapsa and Neomyia cornicina. We also extended the geographic coverage of barcodes of species which hitherto were only sampled from a limited number of localities, e.g. Cynomya mortuorum and Polietes lardarius were each represented by only one barcode sequence from the UK (Kutty et al. 2008). Similarly, barcodes of Muscina levida were until now only available for samples from Canada, Germany (Renaud et al. 2012) and the USA (Nakano and Honda, unpublished). Conversely, barcodes of the other species sampled here were obtained from no more than five European countries. Ideally, a reliable reference library should comprise a large sampling of sequences, not only representing the European dipteran species that are currently used in forensics (whose development times have been studied under different temperature conditions), but also those of potential forensic interest (occurring on carcasses but whose biology has been less studied) and all their close relatives. Currently, 13 species belonging to 10 genera are being used in forensic investigations (Marchenko 2001, Grassberger et al. 2002, Richards et al. 2009, Velásquez et al. 2013). Hence, the geographic coverage of GenBank and BOLD is still far from comprehensive. Yet, we did not observe intraspecific COI divergences of $>1 \%$ at COI, neither among specimens sequenced in this study nor between 
them and their conspecific best matches in the public libraries (intraspecific distances among GenBank sequences were not calculated here). This indicates that geographic coverage does not always have to be complete to allow correct species identification. Nonetheless, a more comprehensive reference library may comprise more haplotypes, allowing a better assessment of the risk of incorrect identifications (Meier et al. 2006). Indeed, an increased sampling can result in a more difficult distinction between some closely related species (Bergsten et al. 2012) and this has considerable importance for courts.

\section{Evaluation of the DNA-based identifications of forensically important flies in Bel- gium and France provided by GenBank and BOLD}

For $86 \%$ of the barcode fragments used as queries, we retrieved highly similar conspecific sequences ( $>99 \%$ similarity) from GenBank and BOLD. The more divergent best matches ( $<99 \%$ similarity) obtained for the remaining $14 \%$ of the queries would have produced either incorrect (Muscina prolapsa and Neomyia cornicina) or doubtful identifications (Fannia) if all best matches were taken into account for identification. The better performance of the best close match method compared to the simple best match method has already been reported (e.g. Meier et al. 2006, Virgilio et al. 2010). However, even with the best close match method, our results revealed three issues that can hamper the DNA-based identification of forensically important flies in Belgium and France using GenBank or BOLD: These databases 1) do not include some fly species of forensic interest, 2) include sequences from misidentified specimens and 3) cannot always discriminate between closely related species. Below, we discuss these three issues in more detail.

\section{1) Species not represented in the libraries}

Our results showed that some fly species collected at Belgian crime scenes are not represented by COI records in GenBank and BOLD. Muscina prolapsa, for which no barcode sequence is present in GenBank, colonises carrion and buried remains (Gunn and Bird 2011, Prado e Castro et al. 2012). Also, the identification of Fannia species of forensic interest (Prado e Castro et al. 2012) is hampered by their limited representation in GenBank and BOLD. Neomyia cornicina is currently not used for PMI estimation but the availability of reference sequences of such species collected on crime scenes can decrease the risk of incorrect identification and help to characterize the entomofauna surrounding the crime scene (Amendt et al. 2007).

\section{2) Sequences from misidentified specimens}

Identifications based on the barcode fragment were ambiguous for $50 \%$ of the queries and for $27 \%$ of the species. Some ambiguous identifications can result from misidenti- 
fied sequences in the libraries and could be corrected after re-examining the voucher specimens (Collins and Cruickshank 2013). In our study, the best matches with sequences from different genera could be the result of misidentifications: records of Musca domestica (GenBank accession number JQ350716) and Chrysomya megacephala (KC135926) matched our sequences of Calliphora vicina and Lucilia ampullacea, respectively.

\section{3) Identification of closely related species}

Still, most ambiguous identifications involved closely related species that are not necessarily incorrectly identified (Stevens et al. 2002, Sonet et al. 2012). For example, Wells et al. (2007) and Wells and Stevens (2008) showed that the barcodes of several specimens of Lucilia cuprina (from Hawaii and Asia) are more similar to those of Lucilia sericata than to those of other Lucilia cuprina specimens. This explains the ambiguous identification obtained here for Lucilia sericata. In some cases, the arbitrary similarity threshold, below which matches cannot be used for identification, is too low. Consequently, best close matches with conspecific and allospecific sequences are considered for identification, even if all conspecific best matches are closer to the query than any of the allospecific ones. To solve this problem, the similarity threshold can be adapted according to the gap between intra- and interspecific distances observed in this particular group of species (Lefébure et al. 2006, Collins and Cruickshank 2013, Puillandre et al. 2012, Virgilio et al. 2012). Here, we only used an arbitrary threshold of $99 \%$ similarity. A stricter similarity threshold (e.g. 99.5\%) would resolve ambiguous identifications obtained for Lucilia ampullacea, for Lucilia sericata (but not when early releases of BOLD are used) and for Cynomya mortuorum (Tables 1 and 2).

Similarity values between the query and its best matches can be calculated using several methods. Here, similarities with GenBank records were determined as 1 - pdistances but no explicit information was found on the exact method used by the IDS of BOLD to determine the similarity values. Even if the IDS of BOLD applied a different method than ours, - distances are standardly corrected using the Kimura 2-parameter model (Kimura 1980) in DNA barcoding (Hebert et al. 2003) - the two searches (1 and 2) using the same queries against the same public records resulted in an identical list of highly similar best matches. Several studies have indeed observed that biases due to different distance calculation methods are less severe with similar sequences than with divergent ones (Collins et al. 2012, Fregin et al. 2012).

\section{Expanding or restricting the search in GenBank and BOLD?}

It is striking that identifications provided by GenBank and BOLD for the barcode fragment were either ambiguous or involved a rather limited number of very similar reference sequences (Figure 1). Therefore, we tested alternative search strategies to optimise the number of best matches and minimise the number of ambiguous identifications. 
For this, we used different options offered by GenBank and BOLD by 1) including early releases from BOLD in the reference library, 2) adding the keyword "barcode" as a query in GenBank and 3) using longer COI sequences as queries in GenBank.

Including early releases as reference sequences in BOLD increased the number of best matches of $>99 \%$ similarity but also increased the proportion of ambiguous identifications (Table 1). Early releases might not have passed all controls that authors and reviewers make in the process of publication (e.g. Schindel et al. 2011). They are therefore more prone to errors. However, their early release allows the detection of errors and inconsistencies before publication, which is an efficient way to improve the quality of the reference libraries. In addition, they largely outnumber the published sequences and may include precious additional information such as rare haplotypes.

In order to improve the search for sequences that have been produced for DNA barcoding purposes, we added the word "barcode" to each query in GenBank. With this procedure, the number of best matches of $>99 \%$ similarity and the proportion of ambiguous matches drastically decreased. The same tendency was observed when longer COI sequences (1412-1534 bp) were used as queries. This is due to the smaller number of reference sequences that are tagged as barcodes or are longer than the standard barcode fragment. Therefore, this kind of search is currently only relevant for the identification of fly species of forensic interest that are well represented by longer COI reference sequences or that are tagged as barcodes. Moreover, longer DNA fragments are not always easy to sequence from degraded forensic samples (Mazzanti et al. 2010). Due to the limited number of best matches of $>99 \%$ similarity retrieved by these two options, it was not possible to assess their benefit when trying to minimise the proportion of ambiguous identifications.

\section{Conclusion}

Even if BOLD and GenBank contain the same public records, they offer different options for optimizing their use as reference libraries. For barcode data, we recommend using the BOLD Identification System and searching the dataset including early-released sequences (Species Level Barcode Records). This option optimises the number of best-matches and allows to verify the quality of the data (published or early-released sequence, barcode compliant or not, link with voucher specimens, etc.). When working with reference material, we encourage the early release of the data and the correction of any mistake detected at this stage (e.g. misidentification). Furthermore, entering sequences into a BOLD project gives access to a workbench with supplementary tools (tables with best matches, best close matches and construction of Neighbour-Joining trees), that are useful for quality control (Ratnasingham and Hebert 2007). If ambiguous identifications are obtained, it is possible to restrict the search to the published sequences only (BOLD or GenBank) or to the sequences that were produced in the framework of the DNA barcoding initiative. Finally, a further validation with other DNA fragments, morphological characters or ecological evidence might be necessary. 
Without such a validation, identifications will remain questionable and can only be applied to more inclusive taxonomic levels (Wilson et al. 2011). Although DNA barcoding has been validated for forensic use (Dawnay et al. 2007), its applicability in forensics clearly depends on the reliability of the data and of the identification method used (Pereira et al. 2010, Linacre et al. 2011).

\section{Acknowledgements}

We wish to thank the teams of the DNA and Microtraces Analysis (NICC), especially Dr. F. Hubrecht, Dr. S. Vanpoucke, and Dr. F. Noel for their support during our work. We also thank the reviewers of the manuscript for their very constructive and pertinent comments. This research is part of the $\mathrm{BC} 42 \mathrm{~W}$ project and was carried out by the Joint Experimental Molecular Unit - JEMU, which is financed by the Belgian Science Policy Office (BELSPO).

\section{References}

Amendt J, Campobasso C, Gaudry E, Reiter C, LeBlanc H, Hall M (2007) Best practice in forensic entomology—standards and guidelines. International Journal of Legal Medicine 121: 90-104. doi: 10.1007/s00414-006-0086-x

Ber-Bienko GI (1988) Keys to the insects of the European part of the USSR fauna, Volume 5 , Smithsonian Institution Libraries and the National Science Foundation, Washington D.C.

Bergsten J, Bilton DT, Fujisawa T, Elliott M, Monaghan MT, Balke M, Hendrich L, Geijer J, Herrmann J, Foster GN, Ribera I, Nilsson AN, Barraclough TG, Vogler AP (2012) The effect of geographical scale of sampling on DNA barcoding. Systematic Biology 61: 851-869. doi: $10.1093 /$ sysbio/sys037

Boehme P, Amendt J, Zehner R (2012) The use of COI barcodes for molecular identification of forensically important fly species in Germany. Parasitology Research 110: 2325-2332. doi: $10.1007 / \mathrm{s} 00436-011-2767-8$

Caine LM, Real FC, Salona-Bordas MI, de Pancorbo MM, Lima G, Magalhaes T, Pinheiro F (2009) DNA typing of Diptera collected from human corpses in Portugal. Forensic Science International 184: e21-3. doi: 10.1016/j.forsciint.2008.10.016

Charabidze D (2012) La biologie des insectes nécrophages et leur utilisation pour dater le décès en entomologie médico-légale. Annales de la Société Entomologique de France 48: 239-252. doi: $10.1080 / 00379271.2012 .10697773$

Collins RA, Boykin LM, Cruickshank RH, Armstrong KF (2012) Barcoding's next top model: an evaluation of nucleotide substitution models for specimen identification. Methods in Ecology and Evolution 3: 457-465. doi: 10.1111/j.2041-210X.2011.00176.x

Collins RA, Cruickshank RH (2013) The seven deadly sins of DNA barcoding. Molecular Ecology Resources 13: 969-975. doi: 10.1111/1755-0998.12046 
D’Assis Fonseca ECM (1968) Diptera Cyclorrhapha Calyptrata: Muscidae. Handbooks for the Identification of British Insects. 10 Ed. Royal Entomological Society of London, London, $119 \mathrm{pp}$.

Dawnay N, Ogden R, McEwing R, Carvalho GR, Thorpe RS (2007) Validation of the barcoding gene COI for use in forensic genetic species identification. Forensic Science International 173:1-6. doi: 10.1016/j.forsciint.2006.09.013

Desmyter S, Gosselin M (2009) COI sequence variability between Chrysomyinae of forensic interest. Forensic Science International, Genetics 3: 89-95. doi: 10.1016/j.fsigen.2008.11.002

Fregin S, Haase M, Olsson U, Alström P (2012) Pitfalls in comparisons of genetic distances: A case study of the avian family Acrocephalidae. Molecular Phylogenetics and Evolution 62: 319-328. doi: 10.1016/j.ympev.2011.10.003

Grassberger M, Reiter C (2002) Effect of temperature on development of Liopygia (=Sarcophaga) argyrostoma (Robineau-Desvoidy) (Diptera: Sarcophagidae) and its forensic implications. Journal of Forensic Sciences 47: 1332-6. doi: 10.1520/JFS15570J

Gregor F, Rozkošný R, Barták M, Vaňhara J (2002) The Muscidae (Diptera) of Central Europe. Folia Facultatis Scientiarum Naturalium Universitatis Masarykianae Brunensis Biologia 107: 1-280.

Gunn A, Bird J (2011) The ability of the blowflies Calliphora vomitoria (Linnaeus), Calliphora vicina (Robineau-Desvoidy) and Lucilia sericata (Meigen) (Diptera: Calliphoridae) and the muscid flies Muscina stabulans (Fallén) and Muscina prolapsa (Harris) (Diptera: Muscidae) to colonise buried remains. Forensic Science International 207: 198-204. doi: 10.1016/j. forsciint.2010.10.008

Guo YD, Cai JF, Li X, Xiong F, Su RN, Chen FL, Liu QL, Wang XH, Chang YF, Zhong M, Wang X, Wen JF (2010) Identification of the forensically important sarcophagid flies Boerttcherisca peregrina, Parasarcophaga albiceps and Parasarcophaga dux (Diptera: Sarcophagidae) based on COII gene in China. Tropical Biomedicine 27: 451-460. http:// www.ncbi.nlm.nih.gov/pubmed/21399586

Guo Y, Cai J, Chang Y, Li X, Liu Q, Wang X, Wang X, Zhong M, Wen J, Wang J (2011) Identification of forensically important sarcophagid flies (Diptera: Sarcophagidae) in China, based on COI and 16S rDNA gene sequences. Journal of Forensic Sciences 56: 1534-1540. doi: 10.1111/j.1556-4029.2011.01882.x

Harvey ML, Gaudieri S, Villet MH, Dadour IR (2008) A global study of forensically significant calliphorids: implications for identification. Forensic Science International 177: 66-76. doi: 10.1016/j.forsciint.2007.10.009

Harvey ML, Dadour IR, Gaudieri S (2003) Mitochondrial DNA cytochrome oxidase I gene: potential for distinction between immature stages of some forensically important fly species (Diptera) in western Australia. Forensic Science International 131: 134-139. doi: 10.1016/S0379-0738(02)00431-0

Hebert PDN, Cywinska A, Ball SL, DeWaard JR (2003) Biological identifications through DNA barcodes. Proceedings of the Royal Society of London B 270: 313-321. doi: $10.1098 /$ rspb.2002.2218

Hebert PDN, (2010) iBOL data \& resource sharing policies, The International Barcode of Life Project (iBOL). http://ibol.org/resources/data-release-policy/ [accessed on 10 Oct 2013] 
Jordaens K, Sonet G, Richet R, Dupont E, Braet Y, Desmyter S (2012) Identification of forensically important Sarcophaga species (Diptera: Sarcophagidae) using the mitochondrial COI gene. International Journal of Legal Medicine 127: 491-504. doi: 10.1007/s00414-012-0767-6

Joseph I, Mathew DG, Sathyan P, Vargheese G (2011) The use of insects in forensic investigations: An overview on the scope of forensic entomology. Journal of Forensic Dental Sciences 3: 89-91. doi: 10.4103/0975-1475.92154

Kimura M (1980) A simple method for estimating evolutionary rates of base substitutions through comparative studies of nucleotide sequences. Journal of Molecular Evolution 16: 111-120. doi: 10.1007/BF01731581

Kutty SN, Pape T, Pont A, Wiegmann BM, Meier R (2008) The Muscoidea (Diptera: Calyptratae) are paraphyletic: Evidence from four mitochondrial and four nuclear genes. Molecular Phylogenetics and Evolution 49: 639-652. doi: 10.1016/j.ympev.2008.08.012

Lefébure T, Douady CJ, Gouy M, Gibert J (2006) Relationship between morphological taxonomy and molecular divergence within Crustacea: Proposal of a molecular threshold to help species delimitation. Molecular Phylogenetics and Evolution 40: 435-447. doi: 10.1016/j. ympev.2006.03.014

Li X, Cai JF, Guo YD, Wu KL, Wang JF, Liu QL, Wang XH, Chang YF, Yang L, Lan LM, Zhong M, Wang X, Song C, Liu Y, Li JB, Dai ZH (2010) The availability of 16 S rRNA for the identification of forensically important flies (Diptera: Muscidae) in China. Tropical Biomedicine 27: 155-166. http://www.msptm.org/files/155_-_166_Li_X.pdf

Linacre A, Gusmão L, Hecht W, Hellmann AP, Mayr WR, Parson W, Prinz M, Schneider PM, Morling N (2011) ISFG: Recommendations regarding the use of non-human (animal) DNA in forensic genetic investigations. Forensic Science International, Genetics 5: 501-505. doi: 10.1016/j.fsigen.2010.10.017

Liu Q, Cai J, Guo Y, Wang X, Gu Y, Wen J, Meng F, Yi W (2011) Identification of forensically significant calliphorids based on mitochondrial DNA cytochrome oxidase I (COI) gene in China. Forensic Science International 207: e64-5. doi: 10.1016/j.forsciint.2011.02.004

Malgorn Y, Coquoz R (1999) DNA typing for identification of some species of Calliphoridae. An interest in forensic entomology. Forensic Science International 102: 111-119. doi: 10.1016/S0379-0738(99)00039-0

Marchenko MI (2001) Medicolegal relevance of cadaver entomofauna for the determination of the time of death. Forensic Science International 120: 89-109. doi: 10.1016/S03790738(01)00416-9

Marinho MAT, Junqueira ACM, Paulo DF, Esposito MC, Villet MH, Azeredo-Espin AML (2012) Molecular phylogenetics of Oestroidea (Diptera: Calyptratae) with emphasis on Calliphoridae: insights into the inter-familial relationships and additional evidence for paraphyly among blowflies. Molecular Phylogenetics and Evolution 65: 840-854. doi: 10.1016/j.ympev.2012.08.007

Mazzanti M, Alessandrini F, Tagliabracci A, Wells JD, Campobasso CP (2010) DNA degradation and genetic analysis of empty puparia: genetic identification limits in forensic entomology. Forensic Science International 195: 99-102. doi: 10.1016/j.forsciint.2009.11.022

Meier R, Shiyang K, Vaidya G, Ng PKL (2006) DNA barcoding and taxonomy in Diptera: a tale of high intraspecific variability and low identification success. Systematic Biology 55: 715-728. doi: $10.1080 / 10635150600969864$ 
Meiklejohn KA, Wallman JF, Dowton M (2011) DNA-based identification of forensically important Australian Sarcophagidae (Diptera). International Journal of Legal Medicine 125: 27-32. doi: 10.1080/10635150600969864

Meiklejohn KA, Wallman JF, Dowton M (2013) DNA barcoding identifies all immature life stages of a forensically important flesh fly (Diptera: Sarcophagidae). Journal of Forensic Sciences 58: 184-187. doi: 10.1111/j.1556-4029.2012.02220.x

Morgulis A, Coulouris G, Raytselis Y, Madden TL, Agarwala R, Schäffer AA (2008) Database indexing for production MegaBLAST searches. Bioinformatics 24: 1757-1764. doi: 10.1093/bioinformatics/btn322

Paradis E (2010) pegas: an R package for population genetics with an integrated-modular approach. Bioinformatics 26: 419-420. doi: 10.1093/bioinformatics/btp696

Park SH, Park CH, Zhang Y, Piao H, Chung U, Kim SY, Ko KS, Yi C-H, Jo T-H, Hwang J-J (2013) Using the developmental gene bicoid to identify species of forensically important blowflies (Diptera: Calliphoridae). BioMed Research International 2013: 538051. doi: $10.1155 / 2013 / 538051$

Pereira F, Carneiro J, van Asch B (2010) A Guide for Mitochondrial DNA Analysis in NonHuman Forensic Investigations. The Open Forensic Science Journal 3: 33-44.

Prado e Castro C, Serrano A, Martins Da Silva P, García MD (2012) Carrion flies of forensic interest: a study of seasonal community composition and succession in Lisbon, Portugal. Medical and Veterinary Entomology 26: 417-431. doi: 10.1111/j.1365-2915.2012.01031.x

Puillandre N, Lambert A, Brouillet S, Achaz G (2012) ABGD, Automatic Barcode Gap Discovery for primary species delimitation. Molecular Ecology 21: 1864-1877. doi: 10.1111/j.1365-294X.2011.05239.x

Ratnasingham S, Hebert PDN (2007) BOLD: The Barcode of Life Data System. Molecular Ecology Notes 7: 355-364. doi: 10.1111/j.1471-8286.2007.01678.x

Renaud AK, Savage J, Adamowicz SJ (2012) DNA barcoding of Northern Nearctic Muscidae (Diptera) reveals high correspondence between morphological and molecular species limits. BMC Ecology 12: 24. doi: 10.1186/1472-6785-12-24

Richards CS, Crous KL, Villet MH (2009) Models of development for blowfly sister species Chrysomya chloropyga and Chrysomya putoria. Medical and Veterinary Entomology 23: 56-61. doi: 10.1111/j.1365-2915.2008.00767.x

Rodriguez WC, Bass WM (1983) Insect activity and its relationship to decay rates of human cadavers in east Tennessee. Journal of Forensic Sciences 28: 423-432. doi: 10.1520/JFS11524J

Rolo EA, Oliveira AR, Dourado CG, Farinha A, Rebelo MT, Dias D (2013) Identification of sarcosaprophagous Diptera species through DNA barcoding in wildlife forensics. Forensic Science International 228: 160-164. doi: 10.1016/j.forsciint.2013.02.038

Rozkošný R, Gregor F, Adrian CP (1997) The European Fanniidae (Diptera). Acta Scientiarum Naturalium Academiae Scientiarum Bohemicae Brno, Nova Series 31: 1-80.

Schindel DE, Stoeckle MY, Milensky C, Trizna M, Schmidt B, Gebhard C, Graves G (2011) Project description: DNA barcodes of bird species in the national museum of natural history, Smithsonian Institution, USA. ZooKeys 152: 87-92. doi: 10.3897/zookeys.152.2473 
Sonet G, Jordaens K, Braet Y, Desmyter S (2012) Why is the molecular identification of the forensically important blowfly species Lucilia caesar and L. illustris (family Calliphoridae) so problematic? Forensic Science International 223: 153-159. doi: 10.1016/j.forsciint.2012.08.020

Sperling FA, Anderson GS, Hickey DA (1994) A DNA-based approach to the identification of insect species used for postmortem interval estimation. Journal of Forensic Sciences 39: 418-427.

Stevens JR, Wall R, Wells JD (2002) Paraphyly in Hawaiian hybrid blowfly populations and the evolutionary history of anthropophilic species. Insect Molecular Biology 11: 141-148. doi: 10.1046/j.1365-2583.2002.00318.x

Szpila K (2012) Key for identification of European and Mediterranean blowflies (Diptera, Calliphoridae) of medical and veterinary importance - adult flies. In: Gennard DE (Ed) Forensic entomology, an introduction. Wiley-Blackwell, Chichester, 77-81.

Tamura K, Peterson D, Peterson N, Stecher G, Nei M, Kumar S (2011) MEGA5: molecular evolutionary genetics analysis using maximum likelihood, evolutionary distance, and maximum parsimony methods. Molecular Biology and Evolution 28: 2731-2739. doi: $10.1093 / \mathrm{molbev} / \mathrm{msr} 121$

Thompson JD, Higgins DG, Gibson TJ (1994) CLUSTAL W: improving the sensitivity of progressive multiple sequence alignment through sequence weighting, position-specific gap penalties and weight matrix choice. Nucleic Acids Research 22: 4673-4680. http:// www.ncbi.nlm.nih.gov/pmc/articles/PMC308517/

Vanin S, Tasinato P, Ducolin G, Terranova C, Zancaner S, Montisci M, Ferrara SD, Turchetto $\mathrm{M}$ (2008) Use of Lucilia species for forensic investigations in Southern Europe. Forensic Science International 177: 37-41. doi: 10.1016/j.forsciint.2007.10.006

Vincent S, Vian JM, Carlotti MP (2000) Partial sequencing of the cytochrome oxydase b subunit gene I: a tool for the identification of European species of blow flies for postmortem interval estimation. Journal of Forensic Sciences 45: 820-823. http://www.ncbi.nlm.nih. gov/pubmed/10914577

Virgilio M, Jordaens K, Breman FC, Backeljau T, De Meyer M (2012) Identifying insects with incomplete DNA barcode libraries, African fruit flies (Diptera: Tephritidae) as a test case. PLoS ONE 7: e31581. doi: 10.1371/journal.pone.0031581

Virgilio M, Backeljau T, Nevado B, De Meyer M (2010) Comparative performance of DNA barcoding across insect orders. BMC Bioinformatics 11: 206. doi: 10.1186/1471-2105-11-206

Velásquez Y, Ivorra T, Grzywacza A, Martínez-Sánchez A, Magańa C, García-Rojo A, Rojo S (2013) Larval morphology, development and forensic importance of Synthesiomyia nudiseta (Diptera: Muscidae) in Europe: a rare species or just overlooked? Bulletin of Entomological Research 103: 98-110. doi: 10.1017/S0007485312000491

Wallman JF, Donnellan SC (2001) The utility of mitochondrial DNA sequences for the identification of forensically important blowflies (Diptera: Calliphoridae) in southeastern Australia. Forensic Science International 120: 60-67. http://www.fsijournal.org/article/ S0379-0738(01)00426-1/abstract

Wang X, Cai J, Guo Y, Chang Y, Wu K, Liu Q, Wang J, Yang L, Lan L, Zhong M, Wang X, Cheng YS, Liu Y, Chen Y, Li J, Zhang J, Peng X (2010) The availability of 16SrDNA 
gene for identifying forensically important blowflies in China. Romanian Journal of Legal Medicine 18: 43-50. doi: 10.4323/rjlm.2010.43

Wells JD, Pape T, Sperling F (2001) DNA-based identification and molecular systematics of forensically important Sarcophagidae (Diptera). Journal of Forensic Sciences 46: 1098-1102. http://www.ncbi.nlm.nih.gov/pubmed/11569549

Wells JD, Sperling FA (1999) Molecular phylogeny of Chrysomya albiceps and C. rufifacies (Diptera: Calliphoridae). Journal of Medical Entomology 36: 222-226. http://www.ncbi. nlm.nih.gov/pubmed/10337087

Wells JD, Sperling FA (2000) A DNA-based approach to the identification of insect species used for postmortem interval estimation and partial sequencing of the cytochrome oxydase $b$ subunit gene I: a tool for the identification of European species of blow flies for postmortem interval. Journal of Forensic Sciences 45: 1358-1359. http://www.ncbi.nlm.nih.gov/ pubmed/11110202

Wells JD, Sperling FAH (2001) DNA-based identification of forensically important Chrysomyinae (Diptera: Calliphoridae). Forensic Science International 120: 110-115. doi: 10.1016/S0379-0738(01)00414-5

Wells JD, Stevens JR (2008) Application of DNA-based methods in forensic entomology. Annual Review of Entomology 53: 103-120. doi: 10.1146/annurev.ento.52.110405.091423

Wells JD, Wall R, Stevens JR (2007) Phylogenetic analysis of forensically important Lucilia flies based on cytochrome oxidase I sequence: a cautionary tale for forensic species determination. International Journal of Legal Medicine 121: 229-233. doi: 10.1007/s00414-006-0147-1

Wells JD, Williams DW (2007) Validation of a DNA-based method for identifying Chrysomyinae (Diptera: Calliphoridae) used in a death investigation. International Journal of Legal Medicine 121: 1-8. doi: 10.1007/s00414-005-0056-8

Whitworth TL, Dawson RD, Magalon H, Baudry E (2007) DNA barcoding cannot reliably identify species of the blowfly genus Protocalliphora (Diptera: Calliphoridae). Proceedings of the Royal Society B 274: 1731-1739. doi: 10.1098/rspb.2007.0062

Wilson JJ, Rougerie R, Schonfeld J, Janzen DH, Hallwachs W, Hajibabaei M, Kitching IJ, Haxaire J, Hebert PDN (2011) When species matches are unavailable are DNA barcodes correctly assigned to higher taxa? An assessment using sphingid moths. BMC Ecology 11: 18. doi: 10.1186/1472-6785-11-18

Zaidi F, Wei S, Shi M, Chen X (2011) Utility of multi-gene loci for forensic species diagnosis of blowflies. Journal of Insect Science 11: 59. doi: 10.1673/031.011.5901

Zehner R, Amendt J, Schütt S, Sauer J, Krettek R, Povolný D (2004) Genetic identification of forensically important flesh flies (Diptera: Sarcophagidae). International Journal of Legal Medicine 118: 245-247. doi: 10.1007/s00414-004-0445-4

Zhang Z, Schwartz S, Wagner L, Miller W (2000) A greedy algorithm for aligning DNA sequences. Journal of Computational Biology 7: 203-214. doi: 10.1089/10665270050081478 